\title{
Win a dream dental chair package
}

A-dec have launched a new 'Picture the Possibilities' competition, where one lucky dentist will win a $£ 30,000$ dream dental chair package!

The prize is completely customisable, with the winning dentist able to choose their preferred A-dec chair, upholstery type and colour, delivery system, LED light and assistant's instrumentation.

The winner can also add their choice of ancillaries, including cameras, handpieces, and motors - up to a total package value of $£ 30,000$ RRP.

One second prize winner will also win a pair of award-winning A-dec 500 dentist's stools, worth $£ 2,405$ RRP. These are available in a choice of 30 sewn upholstery colours.

To enter, simply fill out a short form on the A-dec website and you could be the proud winner of a new dental chair

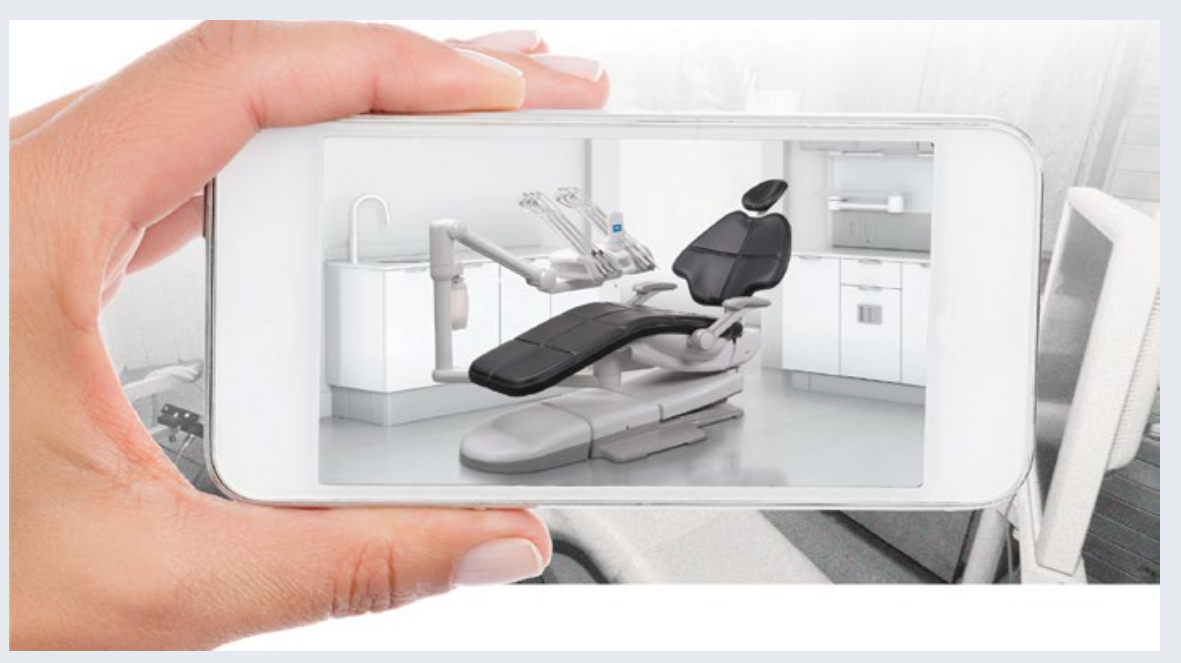

package. Visit www.a-dec.co.uk/possibilities to enter now.

The A-dec 'Picture the Possibilities' prize draw runs until 30 November 2020. Winners will be selected in a random drawing and announced on 4 December 2020. For full terms and conditions, and to enter, visit: www.a-dec.co.uk/possibilities.

\section{Put patient comfort first}

In modern dentistry, patient comfort is a top priority. This is especially true during traditionally more uncomfortable stages of treatment such as impression taking - so why not make it simpler?

Impregum Super Quick polyether impression material from 3M Oral Care combines multiple features to ensure that patients don't feel uncomfortable during this allimportant process.

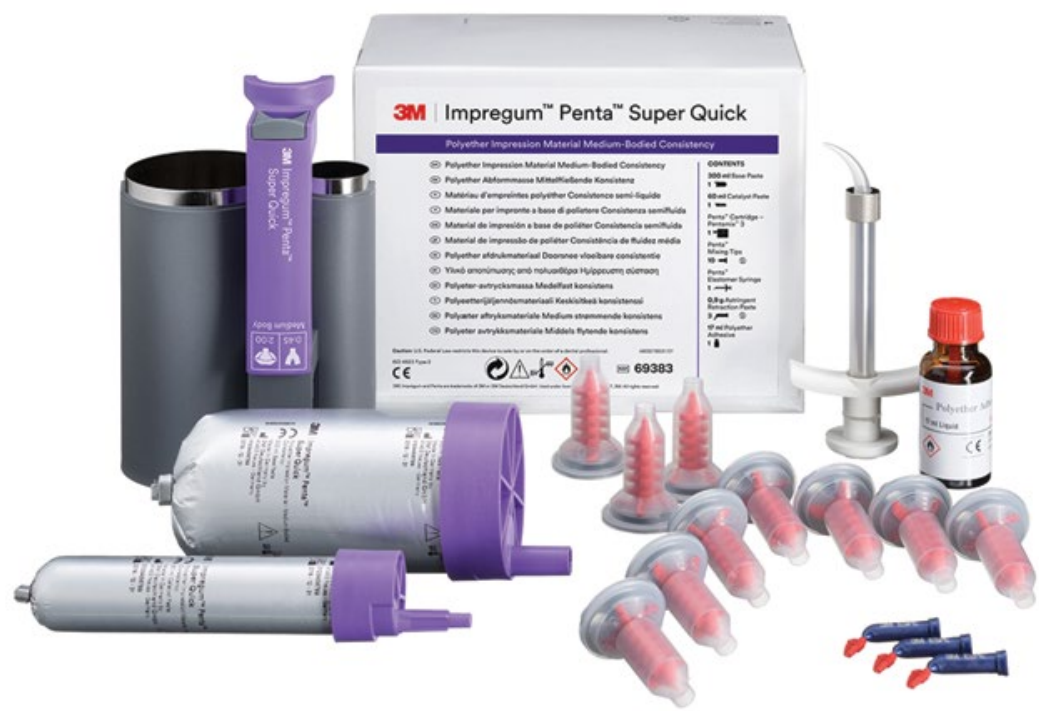

Firstly, Impregum Super Quick polyether impression material from 3M lives up to its name - taking just 45 seconds of working time and two minutes to set. Furthermore, its fresh, minty taste helps to significantly increase patient comfort during the procedure.

Put patients first by contacting $3 \mathrm{M}$ today.

For more information, call 08705360036 or visit www.3M.co.uk/Dental.

$3 \mathrm{M}$ and Impregum are trademarks of the $3 \mathrm{M}$ Company.

\section{The simple way for patients to elevate daily cleaning}

Have you seen TANDEX's new packaging? Tandex has added international standard (ISO) passage hole diameter (PHD) numbers.

- ISO defines a range of PHD spaces that the brush can be squeezed into without deformation

- PHD defines the specific space the brush can be squeezed into without deformation

- PHD is determined by wire and brush diameter, filament thickness, filaments per $\mathrm{cm}$ and how hard the brush is twined.

Each brush size has a unique colour, and this is on the box too.

It's a system that's simple and effective; to elevate daily cleaning, recommend TANDEX to your patients.

For more information on Tandex's range of products, visit tandex.dk. 